\title{
Beyond care burden: associations between positive psychological appraisals and well-being among informal caregivers in Europe
}

\author{
Rebecca Maguire $^{1}$ [D Paul Hanly ${ }^{2} \cdot$ Phil Maguire $^{3}$
}

Accepted: 28 January 2019 / Published online: 4 February 2019

(c) Springer Nature Switzerland AG 2019

\begin{abstract}
Purpose The burden of caring for a family member or friend can have a negative impact on caregiver health and well-being, yet caring can also have positive consequences. Understanding the factors that may enhance caregiver well-being is merited. Methods We used data gathered from the European Quality of Life Survey (EQLS). Using complete case analysis followed by multiple imputation analysis, a series of multilevel regression models were developed to systematically explore the role of three distinct blocks of factors in predicting caregiver well-being as measured by the WHO-5 well-being index: (1) sociodemographic and health factors, (2) care and burden-related factors, and (3) psychological and social appraisals. Differences between frequent caregivers and the general population were also compared on all measures.

Results 36,908 respondents took part in EQLS, with $4171(11 \%)$ identifying as frequent carers. While frequent caregivers reported lower well-being compared to the remaining population, most were happy with the amount of time spent caring. Our model explained approximately $32 \%$ of variance in well-being scores. After examining the role of known risk factors, all positive psychological appraisals were associated with higher well-being $(p<.001)$. In order of magnitude these were optimism, perceived autonomy, sense of purpose, resilience, and perceived levels of social inclusion. Self-rated health was the strongest predictor of well-being while female carers and those with high levels of various burden measures reported lower well-being.

Conclusions Findings suggest that caregiver well-being is influenced by more than simply the burden of care. As well as attempting to reduce burden, interventions aimed at supporting caregivers could focus on fostering more positive appraisals to enhance well-being in this group.
\end{abstract}

Keywords Caregivers $\cdot$ Informal care $\cdot$ Psychological well-being $\cdot$ Burden $\cdot$ Optimism $\cdot$ Resilience $\cdot$ Autonomy

Electronic supplementary material The online version of this article (https://doi.org/10.1007/s11136-019-02122-y) contains supplementary material, which is available to authorized users.

Rebecca Maguire

rebecca.maguire@mu.ie

1 Department of Psychology, Maynooth University, Maynooth, Co. Kildare, Ireland

2 School of Business, National College of Ireland, Dublin, Ireland

3 Department of Computer Science, Maynooth University, Maynooth, Co. Kildare, Ireland

\section{Introduction}

The number of informal caregivers in Europe is increasing, with many older, disabled, or chronically ill individuals now dependent on care from their family members and friends [1-3]. It is widely reported that caring can lead to decrements in the well-being of caregivers themselves [3-7], with caregiving suggested to impact negatively on health $[1,7]$, life satisfaction [8], and overall quality of life [9]. Given that caregivers who report poorer self-rated health and/or depressive symptoms are less likely to provide quality care for patients [10], understanding the factors that may improve caregiver well-being and quality of life is important not only for caregivers themselves, but for their care recipients too $[4,11]$.

The primary focus in the carer well-being literature to date has been on the burden associated with care [12, 13], 
with higher levels of burden thought to account for losses in quality of life in this group [9]. Caregivers are often required to take on diverse roles which can include medical and instrumental tasks, as well as delivering social and emotional support to their care recipients. Burden is often viewed as stemming from the time that caregivers must dedicate to carrying out such tasks [14], which may, in turn, result in restrictions on the amount of time that can be spent on other activities (including, for example, work, leisure, and/or social activities). Aside from such "time-based conflict," the burden of care can lead to "strain-based conflict," where caregiving responsibilities spill over to other aspects of one's life [15]. Previous analysis of European data has also suggested that the extent to which caring impacts on well-being depends on a number of sociodemographic factors $[3,6]$. For example, female caregivers are likely to have lower well-being than males [16], while carers who are employed and have a higher level of education report a higher satisfaction with life [8]. The well-being of carers in comparison to non-carers also varies depending on the country in which they are based which may, in part, owe to variations in the provision of formal services and normative familial values [6]. However, the general consensus is that all caregivers are at risk of poorer health and greater psychological stress, irrespective of the welfare state in which they reside [2].

Despite numerous studies indicating that caregiving may result in negative consequences for well-being, it is clear that this trend does not follow in all cases. Certain factors appear to have the capacity to buffer against the potential negative effects of caring. For example, carers who have larger social support networks and who participate in a greater number of physical and social activities report a higher satisfaction with life [8]. Furthermore, although some studies have reported that caregiving impacts negatively on health, caregivers have, in fact, a lower mortality risk than non-caregivers [17]. Caring can thus be associated with positive consequences, with some carers reporting gains in quality of life, and most reporting at least some benefits from caring [18]. Emerging work such as this suggests that the benefits of providing care and support have been overlooked [19]. Rather than focusing on the factors that decrease well-being during caregiving, it is worth further investigating what factors may enhance well-being in this group.

Less attention has been paid to psychological appraisals made by the caregiver and how these might separately impact on well-being, regardless of the care situation. It is known that appraisals of illness can impact well-being in those who are suffering from chronic health conditions [20-23]. The same is likely to be the case for caregivers. Psychological appraisals can be viewed as the subjective evaluations made by individuals, including their general outlook and expectations (e.g., their degree of optimism), as well as their interpretations of their own capabilities (e.g., their perceived degree of autonomy) and their perceptions of social support [24]. These factors can be viewed as distinct from perceptions of caregiver burden, as they correspond to internal and subjective interpretations made by the caregiver, rather than to objective and directly measurable characteristics of the care situation. Some work has shown that more positive appraisals are associated with better outcomes. For example, patients and caregivers who demonstrate high levels of optimism report a higher level of well-being [25], while those who experience greater resilience adjust more positively to caregiving [26]. Optimism, resilience, and other positive appraisals may thus play an important protective role in how a caregiver interprets the care situation. Understanding the role that these factors play in well-being is worthy of investigation, especially given their potentially modifiable nature.

In this study, we aimed to systematically analyze the contribution of three distinct sets of factors on carer wellbeing using data from the European Quality of Life Survey, with a focus on the role that psychological appraisals may play in this process. Specifically, we were interested in exploring associations between positive psychological and social appraisals with overall carer well-being, in addition to examining a range of sociodemographic characteristics, and various care and burden-related factors. We also aimed to investigate whether frequent caregivers differed to the wider European population on any of these measures, in order to get a clearer picture of caregivers across Europe.

\section{Method}

\section{Participants and design}

This study was based on data collected as part of the 4th European Quality of Life Survey (EQLS) which was conducted in 2016-2017 by the European Foundation for the Improvement of Living and Working Conditions [27]. The EQLS survey is carried out every 4 years, and takes numerous objective and subjective measures of people's working and living conditions in a number of European countries, including all $27 \mathrm{EU}$ member States. A random sample of adults living in private households were approached to take part in the study and interviewed in person, with a minimum sample size of 1000 per country. Informed consent was obtained from all individual participants included in the study. The data from the survey [27] were obtained by the authors via the UK Data Service.

A total of 36,908 respondents took part in the EQLS. For the purpose of this study, we were primarily interested in those who identified as frequent carers. One of the questions on the EQLS required participants to report whether they 
care for disabled or infirm family members, neighbors, or friends under the age of 75 , with another question asking if they care for anyone aged 75 or over. We merged these two categories to get a measure of whether participants engaged in any informal caring. Respondents were also asked to indicate how often they engage in caring: every day, several days a week, once or twice a week, less often or never. As we wished to focus on frequent, rather than occasional, carers, we limited our analysis to those who cared for disabled or infirm family members or friends at least several days a week.

\section{Measures}

\section{Well-being}

The World Health Organisation Mental Well-being index (WHO-5) was used to measure overall subjective well-being in the EQLS sample. This is one of the most widely used and validated measures of psychological well-being [28] and includes five statements where respondents rate the extent to which they have felt a particular way in the past 2 weeks (e.g., "I have felt cheerful and in good spirits" and "I woke up feeling fresh and rested"). Respondents indicated their agreement with each statement on a scale of 1 (all of the time) to 5 (some of the time). Responses were then summed and standardized on a scale of 0-100, with higher scores representing higher well-being. There was good reliability of the WHO-5 across the EQLS sample, with a Cronbach's alpha of 0.891 .

\section{Sociodemographic characteristics and health}

Various measures of respondents' sociodemographic characteristics were taken, including their gender, age, education, and employment status. Whether respondents had a partner living in the household was also measured. Employment status was recoded into two categories (employed/ self-employed or other), while responses for education were recoded into three categories based on The International Standard Classification of Education (ISCED). Specifically, those with any primary education or lower (ISCED 0 or 1) were included in the primary education category; those with any secondary level qualifications, including post-secondary or non-tertiary education (ISCED 2-4), were included in the secondary education category; while those with any third level education (ISCED 5-8) were included in the tertiary education category.

As a further measure of caregiver's economic status, we included the Deprivation Index from the EQLS. This measures the total number of items that a household cannot afford, with respondents asked to indicate whether they could afford six things, specifically "keeping your house adequately warm," "paying for a week's annual holiday away from home (not staying with relatives)," "replacing any worn-out furniture," "a meal with meat, chicken, fish every second day if you wanted it," "buying new, rather than second-hand clothes," and "having friends or family for a drink or meal at least once a month". The Deprivation Index is simply a composite score of the number of items not afforded (ranging from 0 to 6 ), with higher scores indicating higher levels of deprivation.

A measure of self-rated health was also included in light of its known associations with well-being. Here, respondents were asked to indicate how their health was in general on a five point scale, ranging from 1 (very good) to 5 (very bad). In addition, respondents were asked how frequently they took part in sports or physical exercise, on a scale of 1 (every day or almost every day) to 5 (never).

\section{Characteristics of care and burden}

We employed a number of different measures relating to the care situation, including various aspects of burden. While we only focused on those who could be classified as frequent caregivers in this study (i.e., those who cared at least several times a week), we also took into account whether caregivers indicated that they engaged in daily care, in comparison to those who indicated they cared several times a week. This was used as an indicator of the intensity of caregiving responsibilities. In addition, we took into account the age of the care recipient. Caregivers were asked whether they cared for disabled or infirm family members/friends under the age of 75 , and/or those aged 75 years or over. This gave rise to three separate categories: frequent caregivers for those only under the age of 75 , frequent caregivers for those only aged 75 and over, and frequent caregivers for both those under and over the age of 75 .

One item on the EQLS asked respondents about their use of time, which was taken as a proxy of schedule burden. Specifically, respondents were asked to rate their agreement with the following statement: "In my daily life, I seldom have time to do the things that I really enjoy" on a scale of 1 (strongly agree) to 5 (strongly disagree).

We also included two other measures more directly related to the care situation. In one question, employed carers were asked how easy they found it to combine paid work with their care responsibilities, while those not employed were asked to hypothetically consider how easy it would be to combine paid work (say 10 hours per week) with their care responsibilities. Responses ranged from 1 (very easy) to 4 (very difficult). We merged these responses to get an additional measure of the time burden experienced by all carers. Caregivers' overall satisfaction with the care situation was also examined to measure their more subjective experience of burden. Specifically, respondents were asked 
if they would like to spend less time, spend as much time as they currently do, or spend more time, caring. Responses were rated on a scale of $1-3$, with lower scores representing greater perceived burden.

Finally, to measure financial burden, respondents were asked how easy it was for their household to "make ends meet," ranging from 1 (very easily) to 6 (with great difficulty).

\section{Psychological appraisals}

The EQLS included a number of measures of psychological appraisals. These included measures of optimism ("I am optimistic about my future"), purpose ("I generally feel what I do in life is worthwhile"), autonomy ("I feel I am free to decide how to live my life"), and two questions relating to resilience ("I find it difficult to deal with important problems that come up in my life" and "When things go wrong in my life, it generally takes me a long time to get back to normal"). For all these items, respondents rated their agreement on a scale of 1 (strongly agree) to 5 (strongly disagree).

In order to measure respondents' perceptions of social inclusion/exclusion, the Social Exclusion Index was used. This index is based on responses to five items which focus on an individual's appraisals of their social support (e.g., "I feel left out of society" and "I feel that the value of what I do is not recognised by others"). Respondents rate their agreement on a scale of 1 (strongly agree) to 5 (strongly disagree). Responses were summed and then averaged, with lower scores representing more negative appraisals of social support. Reliability was good for items on the scale, with a Cronbach's alpha of 0.72 .

\section{Analysis}

In order to facilitate greater ease of interpretation of the results, scores for a number of measures were recoded and standardized to values ranging from 0 to 100 , so that higher scores represented a greater extent of the particular construct measured. Variables transformed in this way included selfrated health, extent of physical activity, ease of combining care with work, time burden, views on time spent caring, ease of making ends meet, optimism, purpose, autonomy, resilience, and social exclusion (see Fig. 1). Next descriptive statistics were computed, and differences between frequent caregivers and the wider EQLS sample were investigated using Chi square tests for independence (for the categorical variables), and independent $t$ tests (for the continuous variables). Effect sizes were estimated using Cohen's d or Cramer's V.

Given that this study involved a multi-country design, intra-class correlations (ICCs) were calculated to estimate the degree of similarity between caregivers in each country, thereby highlighting any potential clustering within results. This preliminary analysis informed our decision to adopt a multilevel regression approach, which was used to establish the set of covariates that best predicted psychological wellbeing as measured by the WHO-5.

Firstly, using a complete case analysis, an intercept-only (null) model was constructed without any predictor variables to establish the overall variation in well-being scores across countries (Model 1). This was used as a reference for comparing the influence of the various explanatory variables in subsequent models. Three models were constructed in sequence which all included individual predictors as fixed effects, with the intercept specified as a random effect. These models explored the additional roles of sociodemographic and health factors (Model 2), characteristics of care and burden factors (Model 3), and psychological and social appraisals (Model 4), in the ability to predict caregiver well-being (see Fig. 1). All models involved two levels, with caregivers constituting the first level, and country of residence the second level. Because there were multiple countries in the sample, allowing each to assume its own slope would introduce too many free parameters into the analysis and increase the risk of overfitting. We, therefore, assumed that all predictors had the same linear relationship with WHO-5 across countries [29]. Variance participant coefficients were calculated using the restricted maximum likelihood (RML) technique. Explained variance accounted by the models was estimated following the procedure of $\mathrm{Xu}$ [30].

Following the complete case analysis, missing values were imputed using multiple imputation procedures [31]. Specifically, fully conditional specification (FCS) was used which involves an iterative Markov Chain Monte Carlo algorithm to replace missing values, resulting in the creation of multiple data sets $(n=10)$. Data from all ten datasets were analyzed using the same multilevel procedures as with the complete case analysis, with results being combined to produce pooled estimates for the four models (see Supplementary Appendix for additional details).

For both phases of the analysis (complete case analysis and imputed data analysis), associations with the predictor variables and well-being were assessed using two-sided $t$ tests, with significance set conservatively at $p<.001$ to reflect the large sample size. Effect sizes were calculated by measuring the proportion of variance explained by each predictor relative to the proportion of explained variance in well-being scores [32]. Analyses were conducted using SPSS version 22.

\section{Results}

\section{Descriptive statistics and group comparisons}

Overall, 4171 respondents identified as frequent caregivers (i.e., those caring for ill or disabled relatives at least several 
Fig. 1 Explanation of all measures used in the multilevel models

\begin{tabular}{|c|c|}
\hline \multicolumn{2}{|r|}{$\begin{array}{c}\text { Model 1 } \\
\text { (Intercept-only) }\end{array}$} \\
\hline \multicolumn{2}{|r|}{ Country of Residence } \\
\hline \multicolumn{2}{|c|}{$\begin{array}{c}\text { Model 2 } \\
\text { (Adding Caregiver Sociodemographic Factors and Health) }\end{array}$} \\
\hline Variable & Values and interpretation \\
\hline Gender & $0=$ Male; $1=$ Female \\
\hline Age & Age in years $(18+)$ \\
\hline $\begin{array}{l}\text { Education } \\
\text { (dummy coded in model) }\end{array}$ & $\begin{array}{l}\text { Primary education }(0=\text { no; } 1=\text { yes }) \\
\text { Secondary education }(0=\text { no; } 1=\text { yes }) \\
\text { Tertiary education }=\text { reference category }\end{array}$ \\
\hline Employment status & $0=$ Other; $1=$ Employed/Self-employed \\
\hline Deprivation Index & Number of items not afforded (range 0-6) \\
\hline Partner in household & $\begin{array}{l}0=\text { No partner living in household; } 1=\text { partner living in } \\
\text { household }\end{array}$ \\
\hline Self-rated health & Higher $=$ better self-rated health (range $0-100)$ \\
\hline Physical activity & $\begin{array}{l}\text { Extent of physical activity. Higher }=\text { more frequent levels of } \\
\text { physical activity (range } 0-100 \text { ) }\end{array}$ \\
\hline \multicolumn{2}{|c|}{$\begin{array}{c}\text { Model 3 } \\
\text { (Adding Characteristics of Care and Burden) }\end{array}$} \\
\hline Variable & Values and interpretation \\
\hline Care frequency & $0=$ does not provide daily care; $1=$ provides daily care \\
\hline $\begin{array}{l}\text { Age of recipient(s) } \\
\text { (dummy coded model) }\end{array}$ & $\begin{array}{l}\text { Cares for under } 75 \text { only }(0=\text { no; } 1=\text { yes }) \\
\text { Cares for } 75+\text { only }(0=\text { no; } 1=\text { yes }) \\
\text { Cares for both age groups }=\text { reference category }\end{array}$ \\
\hline $\begin{array}{l}\text { Ease of combining care with } \\
\text { work }\end{array}$ & $\begin{array}{l}\text { The ease with which caregivers can (or could hypothetically) } \\
\text { combine care with work. Higher = greater ease (range } 0-100 \text { ) }\end{array}$ \\
\hline Time burden & $\begin{array}{l}\text { Amount of time burden experienced. Higher }=\text { great time } \\
\text { burden (range } 0-100) .\end{array}$ \\
\hline Views on time spent caring & $\begin{array}{l}\text { Extent to which caregiver feels about their time spent caring. } \\
\text { Higher = would like to spend more time (range } 0-100 \text { ) }\end{array}$ \\
\hline Ease of making ends meet & $\begin{array}{l}\text { The ease with which household can make ends meet; Higher }= \\
\text { can make ends meet with greater ease (range } 0-100 \text { ) }\end{array}$ \\
\hline \multicolumn{2}{|c|}{$\begin{array}{c}\text { Model 4 } \\
\text { (Adding Psychological and Social Appraisals) }\end{array}$} \\
\hline Variable & Values and interpretation \\
\hline Optimism & Levels of optimism. Higher $=$ more optimism $($ range $0-100)$ \\
\hline Purpose & $\begin{array}{l}\text { Levels of purpose. Higher }=\text { greater sense of purpose }(\text { range } 0- \\
100)\end{array}$ \\
\hline Autonomy & Levels of autonomy. Higher $=$ more autonomy (range $0-100)$ \\
\hline Resilience & Levels of resilience. Higher $=$ more resilience $($ range $0-100)$ \\
\hline Social Exclusion Index & $\begin{array}{l}\text { Levels of social exclusion. Higher }=\text { greater perception of } \\
\text { social exclusion (range } 0-100)\end{array}$ \\
\hline
\end{tabular}

times a week). This represented $11.3 \%$ of the overall sample of 36,908 respondents.

Tables 1 and 2 display descriptive statistics for the sample of frequent caregivers in comparison to the remainder of the EQLS sample. As can be seen here, caregivers differed from the wider sample on nearly all of the measured variables, as assessed using Chi square tests of independence for categorical variables, and independent sample $t$ tests for continuous variables $(p<.001)$. Caregivers were more likely to be female $(64 \%)$, not employed $(58 \%)$, and have a partner in the household $(64 \%)$. In terms of education, analysis of standardized residuals revealed that caregivers were more likely to have obtained secondary education (65\%), but less likely to have received third level education (24\%) than non-caregivers. Caregivers were also slightly older than the non-caregiving sample and reported slightly worse health, although aside from gender differences and presence of a partner, the magnitude of these differences was small.

When examining characteristics of the care situation, results revealed that $63 \%$ of the sample provided daily care. While the proportion of those caring for those under age $75(39 \%)$ and over $75(35 \%)$ were similar, a significant minority (24\%) reported caring for both age groups. Caregivers reported greater time burden and financial burden than non-caregivers, and were less likely to have time for the things they enjoyed. However, only $12 \%$ of the caregiving sample expressed a desire to spend less time caring, with most reporting they were happy with the 
Table 1 Comparison between frequent caregivers and the wider EQLS sample on categorical measures used

\begin{tabular}{|c|c|c|c|c|c|}
\hline Variable & $\begin{array}{l}\text { Frequent caregivers } \\
N(\%)\end{array}$ & $\begin{array}{l}\text { Remaining sample } \\
N(\%)\end{array}$ & $\chi^{2}$ & Cramer's V & ICC \\
\hline \multicolumn{6}{|l|}{ Gender } \\
\hline Male & $1503(36 \%)$ & $14,299(44 \%)$ & $107.243 * *$ & $.05 * *$ & 0.01 \\
\hline Female & $2668(64 \%)$ & $17,937(56 \%)$ & & & \\
\hline Missing & - & - & & & \\
\hline \multicolumn{6}{|l|}{ Education } \\
\hline Primary or below & $440(11 \%)$ & $3553(11 \%)$ & $18.636^{* * *}$ & $.02 * *$ & 0.06 \\
\hline Second level & $2710(65 \%)$ & $19,925(62 \%)$ & & & \\
\hline Third level & $997(24 \%)$ & $8614(27 \%)$ & & & \\
\hline Missing & $24(.06 \%)$ & $144(.04 \%)$ & & & \\
\hline \multicolumn{6}{|l|}{ Employment status } \\
\hline Employed/self employed & $1742(42 \%)$ & $15,046(47 \%)$ & $37.635^{* *}$ & $.03 * *$ & 0.02 \\
\hline Other & $2429(58 \%)$ & $17,190(53 \%)$ & & & \\
\hline Missing & - & - & & & \\
\hline \multicolumn{6}{|l|}{ Has partner in household } \\
\hline No & $1492(36 \%)$ & $13,556(42 \%)$ & $60.036 * *$ & $.04 * *$ & 0.01 \\
\hline Yes & $2679(64 \%)$ & $18,680(56 \%)$ & & & \\
\hline Missing & - & - & & & \\
\hline \multicolumn{6}{|l|}{ Care frequency } \\
\hline Provides daily care & $2623(63 \%)$ & & & & 0.05 \\
\hline Does not provide daily care & $1548(37 \%)$ & & & & \\
\hline Missing & - & & & & \\
\hline \multicolumn{6}{|l|}{ Age of care recipient } \\
\hline Cares for only under 75 year old & $1615(39 \%)$ & & & & 0.04 \\
\hline Cares for only 75 year old+ & $1465(35 \%)$ & & & & \\
\hline Cares for both age groups & $1091(26 \%)$ & & & & \\
\hline Missing & - & & & & \\
\hline \multicolumn{6}{|l|}{ Views on time spent caring } \\
\hline Would like to spend: & & & & & 0.03 \\
\hline Less time caring & $457(12 \%)$ & & & & \\
\hline Same amount of time caring & $2688(69 \%)$ & & & & \\
\hline More time caring & $773(20 \%)$ & & & & \\
\hline Missing & $253(6 \%)$ & & & & \\
\hline
\end{tabular}

$* * p<.001$. Note: Intra-class correlations (ICCs) are also shown

time spent caring currently. On average, frequent caregivers reported more negative psychological appraisals than the remainder of the EQLS sample, with the exception of sense of purpose, on which they did not differ to the wider sample. Overall, caregivers reported being less optimistic, having less autonomy, and having lower perceived resilience. They were also more likely to feel excluded from society, and had an overall lower well-being as measured by WHO-5. However, again it should be noted that observation of the effect sizes suggested the magnitude of most of these differences was small.

\section{Intra class correlations}

ICCs provide an estimate of the degree of similarity in a specific group, in this case the different countries within the EQLS survey. To this end, ICCs were computed to establish the extent to which caregivers in a given country resembled each other. A large ICC estimate suggests greater homogeneity within clusters, while ICCs close to zero suggest no variance between them. As can be seen in Tables 1 and 2, ICCs were typically low, suggesting that there was little variation between the countries on most of the study measures. 
Table 2 Comparison between frequent caregivers and the wider EQLS sample on continuous measures used

\begin{tabular}{|c|c|c|c|c|c|c|c|c|c|c|c|}
\hline \multirow[t]{2}{*}{ Variable } & \multicolumn{4}{|c|}{ Frequent caregivers } & \multicolumn{4}{|c|}{ Remaining sample } & \multirow[t]{2}{*}{$t$} & \multirow[t]{2}{*}{$d$} & \multirow[t]{2}{*}{ ICC } \\
\hline & Mean & SD & $N$ & Missing (\%) & Mean & $\mathrm{SD}$ & $N$ & Missing (\%) & & & \\
\hline Age & 52.15 & 15.63 & 4171 & $0(0 \%)$ & 50.64 & 17.94 & 32,236 & $0(0 \%)$ & $5.309 * *$ & 0.09 & 0.09 \\
\hline Self-rated health & 66.29 & 23.23 & 4167 & $4(0.1 \%)$ & 68.78 & 23.67 & 32,211 & $25(0.8 \%)$ & $-6.398 * *$ & 0.11 & 0.06 \\
\hline Level of physical activity & 38.78 & 38.23 & 4155 & $16(0.4 \%)$ & 38.90 & 38.40 & 32,091 & $145(0.5 \%)$ & .194 & - & 0.15 \\
\hline Deprivation index & 1.37 & 1.84 & 3955 & $216(5.2 \%)$ & 1.50 & 1.88 & 30,490 & $1746(5.4 \%)$ & $-4.125^{* *}$ & 0.07 & 0.17 \\
\hline Time burden & 52.07 & 29.83 & 4159 & $12(0.3 \%)$ & 47.02 & 29.23 & 32,112 & $124(0.4 \%)$ & $10.465 * *$ & 0.15 & 0.04 \\
\hline Ease of combining care with work & 51.22 & 31.43 & 3893 & $278(6.7 \%)$ & - & - & - & - & - & - & 0.05 \\
\hline Ease of making ends meet & 49.65 & 27.35 & 4144 & $27(0.6 \%)$ & 53.38 & 26.80 & 31,888 & $348(1.1 \%)$ & $-8.398 * *$ & 0.14 & 0.20 \\
\hline Optimism & 62.94 & 26.91 & 4149 & $22(0.5 \%)$ & 65.05 & 25.60 & 32,028 & $208(0.7 \%)$ & $-4.960 * *$ & 0.08 & 0.07 \\
\hline Purpose & 72.34 & 22.53 & 4149 & $22(0.5 \%)$ & 72.19 & 21.76 & 32,062 & $174(0.5 \%)$ & .437 & - & 0.06 \\
\hline Autonomy & 69.14 & 26.46 & 4162 & $9(0.2 \%)$ & 72.47 & 24.19 & 32,176 & $60(0.2 \%)$ & $-8.282 * *$ & 0.13 & 0.05 \\
\hline Resilience & 56.12 & 26.50 & 4122 & $49(1.2 \%)$ & 58.75 & 25.50 & 31,896 & $340(1.1 \%)$ & $-6.193 * *$ & 0.09 & 0.11 \\
\hline Social exclusion index & 33.76 & 22.89 & 4064 & $107(2.6 \%)$ & 29.81 & 21.66 & 31,279 & $957(3 \%)$ & $10.863 * *$ & 0.18 & 0.13 \\
\hline WHO-5 well-being index & 60.84 & 22.60 & 4140 & $31(0.7 \%)$ & 62.85 & 21.17 & 31,974 & $262(0.8 \%)$ & $-5.698 * *$ & 0.09 & 0.06 \\
\hline
\end{tabular}

** $p<.001$. ICCs are also shown. All variables, except Age and Deprivation Index, were standardized to scores of 0-100 (see also Fig. 1 for further explanation)

However, there were some exceptions to this. For example, the observed ICC for participants' ratings of how easy it was to make ends meet $(\mathrm{ICC}=0.20)$, suggests that $20 \%$ of the variance in responses to this question could be attributable to country of residence. Following guidelines [33], when ICCs exceed $10 \%$ of the variance for a given outcome, it is recommended to conduct multi-level analysis.

\section{Multilevel regression models}

Multilevel modelling was applied to control for any possible clustering of the results within countries. Here, country of residence was included as a random effect, with the other variables measured as fixed effects. A similar approach has been adopted in previous work [34]. We first explored the four models previously described using a complete case analysis, which resulted in a loss of $20.4 \%$ of cases $(n=3322)$. To address any possible concerns or biases resulting from missing data, multiple imputation procedures were employed before rerunning the analysis with the imputed data $(n=4171)$. Table 3 includes the variance estimates for each of the four multilevel models resulting from both the complete case analysis and multiple imputation analysis. As estimations were broadly similar for both analyses, we focus below on the estimates resulting from the observed data.

The intercept-only model (Model 1) found that the greatest proportion of variance in well-being scores was at the individual level (94\%), with only $6 \%$ of the variance attributable to the country level. Subsequent models were then constructed in order to explore the role of the three separate sets of factors in explaining well-being. As can be seen in Table 3, the addition of sociodemographic and health-related factors (Model 2) contributed to approximately 17\% of the variance in well-being scores. The addition of care and burden factors (Model 3) explained an additional $8 \%$ of the variance, while the inclusion of psychological and social appraisals (Model 4) explained a further $8 \%$ of variance in well-being scores.

Table 3 Contribution of each model to caregiver well-being using complete case analysis and imputed data analysis

\begin{tabular}{|c|c|c|c|c|c|}
\hline & & $\begin{array}{l}\text { Model } 1 \\
\text { (intercept only } \\
\text { model) }\end{array}$ & $\begin{array}{l}\text { Model } 2 \text { (sociodemo- } \\
\text { graphic and health factors } \\
\text { added) }\end{array}$ & $\begin{array}{l}\text { Model } 3 \text { (care and } \\
\text { burden factors } \\
\text { added) }\end{array}$ & $\begin{array}{l}\text { Model } 4 \text { (psychological } \\
\text { and social appraisals } \\
\text { added) }\end{array}$ \\
\hline \multirow{3}{*}{$\begin{array}{l}\text { Complete case analysis } \\
\quad(n=3322)\end{array}$} & Residual & 470.95 & 390.85 & 355.55 & 318.72 \\
\hline & Intercept (country) & 25.09 & 18.45 & 10.11 & 10.03 \\
\hline & Explained variance & & $17.01 \%$ & $24.50 \%$ & $32.32 \%$ \\
\hline \multirow{3}{*}{$\begin{array}{l}\text { Imputed Data Analysis } \\
\text { (ten imputed datasets; } \\
n=4171 \text { ) }\end{array}$} & Residual & 483.89 & 391.2 & 354.3 & 317.34 \\
\hline & Intercept (country) & 27.56 & 20.36 & 12.07 & 11.78 \\
\hline & Explained variance & & $19.16 \%$ & $26.78 \%$ & $34.42 \%$ \\
\hline
\end{tabular}


Table 4 displays the results for the final multilevel model using the complete case analysis. A total of $32 \%$ of the variance was explained here. Nine of the predictor variables were significantly associated with higher levels of wellbeing $(p<.001)$. Examination of effect sizes revealed that, in order of magnitude, these were: higher self-rated health (coefficient $=0.265 ; d=0.09$ ), greater ease of making ends meet (coefficient $=0.104 ; d=0.02$ ), higher levels of optimism (coefficient $=0.113 ; d=0.02$ ), more autonomy (coefficient $=0.094 ; d=0.01$ ), greater sense of purpose (coefficient $=0.088 ; d=0.01$ ), more resilience (coefficient $=0.053$; $d=0.01$ ), and greater ease of combining care with work (coefficient $=0.083 ; d=0.004$ ). Being male, as opposed to female (coefficient $=-2.469 ; d=0.01$ ), and having a lower time burden (coefficient $=-0.040 ; d=0.003$ ), were also associated with higher well-being, however, effect sizes were small here. Results using the imputed data analysis were similar and can be viewed in the Supplementary Online Appendix. The only difference between this and the complete case analysis was that social exclusion index emerged as a further significant predictor at the $p<.001$ level.
Specifically, greater social exclusion was associated with lower levels of well-being.

\section{Discussion}

The results of this study reveal some interesting observations regarding the potential factors that impact on the well-being of informal caregivers. Firstly, in line with previous work [3-6], we have shown that those engaging in frequent caregiving experience lower well-being than those who do not. Given that a significant proportion of the European population identify as frequent caregivers, this finding may at first appear worrying, especially since caregivers also reported poorer heath and experienced greater financial pressures than the wider sample. However, it is also important to note that many caregivers experienced high levels of well-being in spite of their caring duties, and also that the magnitude of any differences observed between frequent caregivers and the wider European sample was small. Our findings suggest that psychological appraisals play an important protective
Table 4 Estimates of fixed effects for the full multilevel model using complete case analysis $(N=3322)$

\begin{tabular}{lrrrllrrr}
\hline Variables & Coefficient & SE & \multicolumn{1}{l}{$T$} & $p$ & $d$ & $95 \%$ CI \\
\hline Intercept & 16.415 & 3.242 & 5.064 & 0.000 & & 10.059 & 22.771 \\
Sociodemographic factors and health & & & & & & & \\
Gender & -2.469 & 0.665 & -3.715 & $0.000^{* *}$ & 0.004 & -3.772 & -1.166 \\
Age & -0.015 & 0.025 & -0.573 & 0.567 & 0.000 & -0.064 & 0.035 \\
Primary education & -0.524 & 1.325 & -0.396 & 0.692 & 0.001 & -3.122 & 2.073 \\
Secondary education & 1.260 & 0.785 & 1.606 & 0.108 & - & -0.278 & 2.799 \\
Employment status & -1.959 & 0.727 & -2.696 & 0.007 & 0.002 & -3.384 & -0.534 \\
Deprivation index & 0.371 & 0.187 & 1.984 & 0.047 & 0.000 & 0.004 & 0.738 \\
Partner in household & 1.028 & 0.672 & 1.532 & 0.126 & 0.000 & -0.288 & 2.345 \\
Self-rated health & 0.265 & 0.016 & 17.006 & $0.000^{* *}$ & 0.086 & 0.234 & 0.295 \\
Physical activity & 0.002 & 0.009 & 0.242 & 0.809 & 0.000 & -0.015 & 0.020 \\
Characteristics of care and burden & & & & & & & \\
Care frequency & -1.657 & 0.674 & -2.458 & 0.014 & 0.002 & -2.979 & -0.336 \\
Cares for under 75s only & -2.090 & 0.805 & -2.597 & 0.009 & 0.001 & -3.668 & -0.512 \\
Cares for 75+ only & -1.303 & 0.848 & -1.536 & 0.125 & - & -2.965 & 0.360 \\
Ease of combining care with work & 0.083 & 0.011 & 7.694 & $0.000^{* *}$ & 0.007 & 0.062 & 0.104 \\
Time burden & -0.040 & 0.011 & -3.534 & $0.000^{* *}$ & 0.003 & -0.063 & -0.018 \\
Views on time caring & 0.880 & 0.568 & 1.548 & 0.122 & 0.000 & -0.234 & 1.994 \\
Ease of making ends meet & 0.104 & 0.014 & 7.299 & $0.000^{* *}$ & 0.020 & 0.076 & 0.132 \\
Psychological and social appraisals & & & & & & & \\
Optimism & 0.113 & 0.015 & 7.771 & $0.000^{* *}$ & 0.017 & 0.085 & 0.142 \\
Purpose & 0.088 & 0.018 & 4.893 & $0.000^{* *}$ & 0.009 & 0.053 & 0.123 \\
Autonomy & 0.094 & 0.015 & 6.356 & $0.000^{* *}$ & 0.012 & 0.065 & 0.122 \\
Resilience & 0.053 & 0.014 & 3.764 & $0.000^{* *}$ & 0.007 & 0.026 & 0.081 \\
Social exclusion index & -0.050 & 0.017 & -2.955 & 0.003 & 0.006 & -0.084 & -0.017 \\
\hline
\end{tabular}

Dependent variable $=$ WHO-5 well-being index. Refer Fig. 1 for an explanation of all variables and their scoring

$* * p<.001$ 
role in maintaining well-being after accounting for sociodemographic and objective risk factors. This extends upon previous research in uncovering the complex combination of elements that can impact on caregiver quality of life.

\section{Burden of care and groups at risk of lower well-being}

While the main focus in our study was on the role that appraisals may play in enhancing well-being, we also wished to examine how well-being would vary with sociodemographic factors and perceptions of caregiver burden. While many of the measured sociodemographic variables were not significantly associated with well-being in our analysis, one notable exception was gender, with female caregivers reporting a lower well-being than males. This finding is in line with previous work which suggests that female caregivers are at a greater risk of lower well-being overall [16]. Also, perhaps unsurprisingly, poorer self-rated health was the strongest associate of lower well-being. Given that carers are often older, worsening health is likely to be a concern within this group and should thus be acknowledged in any intervention designed to support caregivers.

Regardless of sociodemographic differences, lower wellbeing in carers is most typically attributed to the high levels of burden experienced [3, 12]. Consistent with this body of work, our analysis revealed that the burden experienced by caregivers, including general time and financial burden, was negatively associated with well-being. However, another important observation from our analysis is that the vast majority of caregivers reported a high level of satisfaction with the time that they spent caring, with $20 \%$ even expressing a desire to spend more time caring. This argues against the stereotype of carers reluctantly taking on duties and being unhappy due to the burden of care placed on them.

\section{Psychological and social appraisals as protective factors}

Our analysis was designed so that we could examine the impact that psychological appraisals have on well-being after accounting for the above known socio-demographic, health, and care-related burden predictors. Our results have shown that even after these factors were accounted for, every one of the measured psychological appraisals was independently related to well-being. The strongest associate here was optimism, which emerged as a notable predictor of wellbeing in the final model. Many studies report that individuals with a more optimistic outlook have better outcomes [25]. It might be expected that carers would find it more difficult to be optimistic and, consistent with this view, we did find that caregivers held a slightly less optimistic outlook than the overall sample. However, this cannot be simply accounted for by the burden of care. Lower levels of optimism in this group may reflect the fact that caring for a family member or friend with a chronic health condition or disability can be associated with a number of uncertainties [35], which may lead to increased fear and anxiety. For example, cancer caregivers often experience fears that the cancer will recur or progress, which impacts negatively on their well-being [36]. Nevertheless, fears may not always be grounded in clinical risk. It is possible that interventions aimed at reducing fears, and potentially increasing optimism, may provide a means of maintaining well-being in both caregivers and their care recipients. Similarly, other studies suggest that psychological appraisals such as hope can be beneficial for caregivers [37]. We can thus postulate that hope and optimism may be facilitated by providing caregivers with more accurate and reliable information about their care recipients' condition, and presenting this information in a positive, rather than a negative, framework.

Our findings also demonstrate that caregivers who experienced greater levels of autonomy reported better well-being overall. Autonomy, or perceived degree of freedom or control, is a well-established associate of well-being. For example, the degree of perceived control that employees have at work or at home has been shown to moderate the relationship between work demands and stress [38]. Autonomy is also related to the concept of self-regulation, which has been shown to play an important role in general well-being [20]. Our analysis suggests that, overall, caregivers reported lower levels of autonomy than non-caregivers. However, while caregivers may experience a reduction in autonomy after taking on caring duties, research has shown that they often adjust over time and identify new strategies which can enable them to gain control within their lives [39]. While sense of autonomy may be influenced by the objective circumstances of care, our findings suggest that this is fundamentally a subjective assessment of one's situation that acts separately to caregiver burden. It seems feasible that caregivers could be given the tools to develop more effective strategies for managing their time, thereby increasing their perceptions of autonomy.

Similarly, our findings reveal that a caregiver's level of resilience may act as a protective factor for well-being. The importance of fostering resilience in caregivers has recently been acknowledged [26, 35, 40-42]. Our results suggest that carers could be supported by imparting them with beneficial coping strategies for dealing with unforeseen challenges, or by developing greater self-compassion [43]. We have also shown that those carers who feel that what they do in life is worthwhile have higher levels of well-being. Instilling and maintaining this sense of purpose may assist them in delivering support to their care recipients.

Finally, in addition to individual psychological appraisals, we also examined caregiver's social appraisals. It is 
well established that social support can buffer negative effects on well-being, with perceptions of the availability of support being of particular importance. Using the social exclusion index, we found that caregivers who experienced better social inclusion had a higher level of well-being. Given that, relative to the overall EQLS sample, frequent caregivers reported higher levels of social exclusion, it may be appropriate to focus on enhancing perceptions of support in caregivers. Along with positive psychological appraisals, appraisals of social support may impact the likelihood that caregivers will seek out support, thus playing an important role in their well-being [24].

\section{Limitations}

It is important to acknowledge that this study has some limitations. Firstly, our analysis was based on one cross-sectional sample, thus preventing us from assessing how general caregiver well-being may change over time. In addition, while the EQLS allowed many aspects of individual experience and characteristics to be measured (e.g. caregiver burden, appraisals and social context), aside from their broad age bracket, no additional information was provided on the care recipient. It is well established that the patient's health and quality of life are strong contributors to the caregiver's quality of life [14]. The patient's illness appraisal may also have an influence on that of the caregiver [44] so, had we been able to account for this factor in our model, we may have been able to explain a greater amount of variance. Also, while the WHO-5 is an established measure of well-being, it arguably only covers "hedonia" and there are other ways in which psychological well-being may be operationalized. Furthermore, it is important to acknowledge that many of our measures of burden (e.g., time and financial burden) may have related to factors other than the caregiving situation. For example, aside from the frequency in which they engaged in care, we did not know whether caregivers had any help or whether they were the sole carer for the care recipient. Finally, while our focus here was targeted on individual caregiver experience, it seems likely that differences in cultural factors and health care systems across various countries may have further impacted on well-being.

\section{Conclusions}

The question of how best to support caregivers in their duties presents a challenge for those working in healthcare with many interventions attempting to reduce the burden of care placed on this group. However, while our study suggests that burden is clearly associated with quality of life, our findings imply that it is not the only factor that should be acknowledged when considering how to enhance caregiver well-being. Examination of existing policy suggests that rather than financial support, policies enabling carers to free up time, help them deal emotionally with caregiving, and provide them with the skills to improve the care situation, have the greatest impact on well-being [1]. In line with these observations, our study has also shown that caregiver outlook, along with perceptions of support, may play an important role in determining well-being. Interventions aimed at supporting carers might thus consider means of facilitating positive psychological appraisals of the care situation in order to enhance well-being in this group.

\section{Compliance with ethical standards}

Conflict of interest All authors declare that they have no conflicts of interest.

Ethical approval Ethical approval to conduct the current analysis was granted by Maynooth University (Reference Number SREC-2018-084). For the EQLS, all procedures performed in studies involving human participants were in accordance with the ethical standards of the institutional and/or national research committee and with the 1964 Helsinki declaration and its later amendments or comparable ethical standards.

Informed consent Informed consent was obtained from all individual participants included in the EQLS survey (see [26] for details).

Research involving human and animal participants This article does not contain any studies with human participants or animals performed by any of the authors; however, this does involve secondary analysis performed on a dataset that involved human participants.

\section{References}

1. Calvo-Perxas, L., Vilalta-Franch, J., Litwin, H., Turro-Garriga, O., Mira, P., \& Garre-Olmo, J. (2018). What seems to matter in public policy and the health of informal caregivers? A cross-sectional study in 12 European countries. PLOS ONE, 13(3), e0194232. https://doi.org/10.1371/journal.pone.0194232.

2. Kaschowitz, J., \& Brandt, M. (2017). Health effects of informal caregiving across Europe: A longitudinal approach. Social Science \& Medicine, 173, 72-80. https://doi.org/10.1016/j.socsc imed.2016.11.036.

3. Verbakel, E., Tamlagsronning, S., Winstone, L., Fjaer, E., \& Eikemo, T. (2017). Informal care in Europe: Findings from the European Social Survey (2014) special module on the social determinants of health. European Journal of Public Health, 27, 90-95. https://doi.org/10.1093/eurpub/ckw229.

4. Gately, M., \& Ladin, K. (2018). Family and other caregivers. In T. Daaleman \& M. Helton (Eds.), Chronic illness care. Cham: Springer.

5. Pinquart, M., \& Sorensen, S. (2003). Differences between caregivers and noncaregivers in psychological health and physical health: A meta-analysis. Psychology and Aging, 18(2), 250-267. https:// doi.org/10.1037/0882-7974.18.2.250.

6. Verbakel, E. (2014). Informal caregiving and well-being in Europe: What can ease the negative consequences for caregivers? Journal of European Social Policy, 24(5), 424-441. https:// doi.org/10.1177/0958928714543902. 
7. Berglund, E., Lytsy, P., \& Westerling, R. (2015) Health and wellbeing in informal caregivers and non-caregivers: A comparative cross-sectional study of the Swedish a general population. Health and Quality of Life Outcomes. https://doi.org/10.1186/s1295 5-015-0309-2.

8. De Oliveira, D. C., \& Hlebec, V. (2016). Predictors of satisfaction with life in family carers: Evidence from the third European Quality of Life Survey. Teorija in Praksa, 53(2), 503-523.

9. Rafnsson, S., Shankar, A., \& Steptoe, A. (2017). Informal caregiving transitions, subjective well-being and depressed mood: Findings from the English Longitudinal Study of Ageing. Aging \& Mental Health, 21(1), 104-112. https://doi.org/10.1080/13607 863.2015.1088510.

10. Litzelman, K., Kent, E., Mollica, M., \& Rowland, J. (2016). How does caregiver well-being relate to perceived quality of care in patients with cancer? Exploring associations and pathways. Journal of Clinical Oncology, 34(29), 3554-3554+. https://doi. org/10.1200/JCO.2016.67.3434.

11. Sullivan, A. B., \& Miller, D. (2015). Who is taking care of the caregiver? Journal of Patient Experience, 2(1), 7-12. https://doi. org/10.1177/237437431500200103.

12. Adelman, R., Tmanova, L., Delgado, D., Dion, S., \& Lachs, M. (2014). Caregiver burden-A clinical review. JAMA-Journal of the American Medical Association, 311(10), 1052-1059. https:// doi.org/10.1001/jama.2014.304.

13. Bastawrous, M. (2013). Caregiver burden-A critical discussion. International Journal of Nursing Studies, 50(3), 431-441. https:// doi.org/10.1016/j.ijnurstu.2012.10.005.

14. Maguire, R., Hanly, P., Hyland, P., \& Sharp, L. (2018) Understanding burden in caregivers of colorectal cancer survivors: What role do patient and caregiver factors play? European Journal of Cancer Care (England). https://doi.org/10.1111/ecc.12527.

15. Verbakel, E. (2018). How to understand informal caregiving patterns in Europe? The role of formal long-term care provisions and family care norms. Scandinavian Journal of Public Health, 46(4), 436-447. https://doi.org/10.1177/1403494817726197.

16. Ruppanner, L., \& Bostean, G. (2014). Who cares? Caregiver wellbeing in Europe. European Sociological Review, 30(5), 655-669. https://doi.org/10.1093/esr/jcu065.

17. O'Reilly, D., Rosato, M., Maguire, A., \& Wright, D. (2015). Caregiving reduces mortality risk for most caregivers: A censusbased record linkage study. International Journal of Epidemiology, 44(6), 1959-1969. https://doi.org/10.1093/ije/dyv172.

18. Roth, D., Fredman, L., \& Haley, W. (2015). Informal caregiving and its impact on health: A reappraisal from population-based studies. Gerontologist, 55(2), 309-319. https://doi.org/10.1093/ geront/gnu177.

19. Inagaki, T., \& Orehek, E. (2017). On the benefits of giving social support: When, why, and how support providers gain by caring for others. Current Directions in Psychological Science, 26(2), 109-113. https://doi.org/10.1177/0963721416686212.

20. Leventhal, H. O. R., Brissette, I., \& Leventhal, E. A. (2003). The common-sense model of self-regulation of health and illness. In L. Cameron \& H. Leventhal (Eds.), The self-regulation of health and illness behaviour (pp. 42-65). New York: Routledge.

21. Chambers, S., Baade, P., Youl, P., Aitken, J., Occhipinti, S., Vinod, S., Valery, P., Garvey, G., Fong, K., Ball, D., Zorbas, H., Dunn, J., \& O'Connell, D. (2015). Psychological distress and quality of life in lung cancer: The role of health-related stigma, illness appraisals and social constraints. Psycho-oncology, 24(11), 1569-1577. https://doi.org/10.1002/pon.3829.

22. Maguire, R., Hanly, P., Drummond, F. J., Gavin, A., \& Sharp, L. (2018). Expecting the worst? The relationship between retrospective and prospective appraisals of illness on quality of life in prostate cancer survivors. Psychooncology, 27(4), 1237-1243. https://doi.org/10.1002/pon.4660.
23. Moskowitz, J., Wrubel, J., Hult, J., Maurer, S., \& Acree, M. (2013) Illness appraisals and depression in the first year after HIV diagnosis. PLoS ONE. https://doi.org/10.1371/journ al.pone.0078904.

24. Hanks, R., Rapport, L., \& Vangel, S. (2007). Caregiving appraisal after traumatic brain injury: The effects of functional status, coping style, social support and family functioning. Neurorehabilitation, 22(1), 43-52.

25. Scheier, M. F., Carver, C. S., \& Bridges, M. W. (2001). Optimism, pessimism, and psychological well-being. Optimism and Pessimism: Implications for Theory, Research, and Practice, 1, 189-216.

26. Dias, R., Santos, R. L., Sousa, M. F., Nogueira, M. M., Torres, B., Belfort, T., \& Dourado, M. C. (2015). Resilience of caregivers of people with dementia: A systematic review of biological and psychosocial determinants. Trends in Psychiatry Psychotherapy, 37(1), 12-19. https://doi.org/10.1590/2237-6089-2014-0032.

27. Conditions. EFftIoLaW (2018) European Quality of Life Survey integrated data file, 2003-2016 [data collection] (3rd ed.). https:// doi.org/10.5255/UKDA-SN-7348-3

28. Topp, C., Ostergaard, S., Sondergaard, S., \& Bech, P. (2015). The WHO-5 Well-Being Index: A systematic review of the literature. Psychotherapy and Psychosomatics. https://doi. org/10.1159/000376585.

29. Burnham, K., \& Anderson, D. (2002). Model selection and multimodel inference (2nd ed.). New York, NY: Springer.

30. Xu, R. (2003). Measuring explained variation in linear mixed effects models. Statistics in Medicine, 22(22), 3527-3541.

31. Little, R. J., \& Rubin, D. B. (2014). Statistical analysis with missing data, vol 333. Hoboken: Wiley.

32. Lorah, J. (2018). Effect size measures for multilevel models: Definition, interpretation, and TIMSS example. Large-Scale Assessments in Education, 6(1), 8.

33. Lee, V. E. (2000). Using hierarchical linear modeling to study social contexts: The case of school effects. Educational Psychologist, 35(2), 125-141.

34. Kamradt, M., Krisam, J., Kiel, M., Qreini, M., Besier, W., Szecsenyi, J., \& Ose, D. (2017). Health-related quality of life in primary care: Which aspects matter in multimorbid patients with type 2 diabetes mellitus in a community setting? PLOS ONE, 12(1), e0170883.

35. van Wijngaarden, E., van der Wedden, H., Henning, Z., Komen, R., \& The, A. M. (2018). Entangled in uncertainty: The experience of living with dementia from the perspective of family caregivers. PLoS ONE, 13(6), e0198034. https://doi.org/10.1371/ journal.pone.0198034.

36. Maguire, R., Hanly, P., Balfe, M., Timmons, A., Hyland, P., O'Sullivan, E., Butow, P., \& Sharp, L. (2017). Worry in head and neck cancer caregivers: The role of survivor factors, care-related stressors, and loneliness in predicting fear of recurrence. Nursing Research, 66(4), 295-303. https://doi.org/10.1097/NNR.00000 00000000223.

37. Hellman, C. M., Worley, J. A., \& Munoz, R. T. (2018). Hope as a coping resource for caregiver resilience and well-being. In W. Bailey \& A. Harrist (Eds.), Family caregiving. emerging issues in family and individual resilience. Cham: Springer.

38. Halinski, M., Duxbury, L., \& Higgins, C. (2018). Working while caring for mom, dad, and junior too: Exploring the impact of employees' caregiving situation on demands, control, and perceived stress. Journal of Family Issues. https://doi. org/10.1177/0192513X18777839.

39. Lou, S., Carstensen, K., Jorgensen, C. R., \& Nielsen, C. P. (2017). Stroke patients' and informal carers' experiences with life after stroke: An overview of qualitative systematic reviews. Disability and Rehabilitation, 39(3), 301-313. https://doi.org/10.3109/09638 288.2016.1140836. 
40. Elliott, T., Berry, J., Richards, J., \& Shewchuk, R. (2014). Resilience in the initial year of caregiving for a family member with a traumatic spinal cord injury. Journal of Consulting and Clinical Psychology, 82(6), 1072-1086. https://doi.org/10.1037/a0037593.

41. Roen, I., Stifoss-Hanssen, H., Grande, G., Brenne, A. T., Kaasa, S., Sand, K., \& Knudsen, A. K. (2018) Resilience for family carers of advanced cancer patients-how can health care providers contribute? A qualitative interview study with carers. Palliative Medicine. https://doi.org/10.1177/0269216318777656.

42. Limardi, S., Stievano, A., Rocco, G., Vellone, E., \& Alvaro, R. (2016). Caregiver resilience in palliative care: A research protocol. Journal of Advanced Nursing, 72(2), 421-433. https://doi. org/10.1111/jan.12829.

43. Lloyd, J., Muers, J., Patterson, T. G., \& Marczak, M. (2018). Selfcompassion, coping strategies, and caregiver burden in caregivers of people with dementia. Clinical Gerontologist. https://doi. org/10.1080/07317115.2018.1461162.

44. Helgeson, V., Jakubiak, B., Van Vleet, M., \& Zajdel, M. (2018). Communal coping and adjustment to chronic illness: Theory update and evidence. Personality and Social Psychology Review, 22(2), 170-195. https://doi.org/10.1177/1088868317735767.

Publisher's Note Springer Nature remains neutral with regard to jurisdictional claims in published maps and institutional affiliations. 